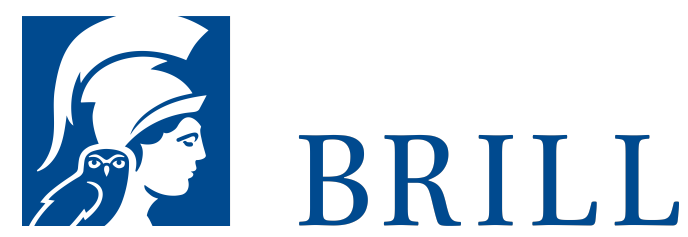

\title{
Aus der Welt gefallen
}

Die Geographie der Verschollenen

Authors: Kristina Kuhn and Wolfgang Struck

Im Archiv des Gothaer Perthes Verlages lagern Materialien, die ein Wissen von der Welt modellieren, so wie es die Fachzeitschrift "Petermanns Geographische Mitteilungen" im 19. Jahrhundert ihrem europaweiten Publikum präsentierte. Das Archiv versam-melt Korrespondenzen und Karten, wissensgeschichtlich spannungsvolles, multimedial angelegtes Material, und verwaltet Geschichten des Verschollengehens als gleichermaßen literar-ische wie nationenbildende Ereignisse. Zwischen Philologie, Wissens- und Kulturgeschichte angesiedelt, rekonstruiert das Buch eine Kunst des Verschollengehens, die im 19. Jahrhundert Geographie, Kartographie und realistische Literatur gleichermaßen fasziniert.

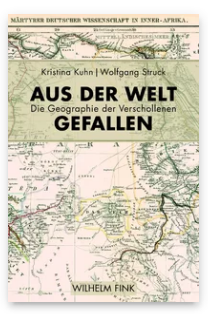

Published: 12

Oct 2020

Pages: VIII + 203 Seiten, 10 s/w und 13 farb. Abb.

Subjects:

History of

Linguistics \&

Philosophy of

Language,

Languages and

Linguistics

Publisher: Brill |

Fink

E-Book (PDF)

ISBN: 978-3-

8467-6o8o-2

Paperback

ISBN: 978-3-

7705-6o8o-6

Price: 
Kristina Kuhn ist als Postdoktorandin, Wissenschaftliche Koordinatorin sowie in der Lehre an der Universität Erfurt tätig. Wolfgang Struck ist Professor für Neuere Deutsche Literaturwissenschaft an der Universität Erfurt.

Please send your order to: Brockhaus/Commission Tel: +49(o)71 541327 9216 | E-Mail: brill@ $\underline{\text { brocom.de }}$

For questions please contact: Brill Deutschland GmbH Wollmarktstraße 115 | 33098 Paderborn | Germany

Tel: +49 (o)5251 69975 o | E-Mail: sales@brill.com. 